\title{
Can Global Liquidity Forecast Asset Prices?
}

\author{
Reginald Darius and Sören Radde
}




\title{
IMF Working Paper
}

\author{
Strategy, Policy, and Review Department and DIW Berlin
}

Can Global Liquidity Forecast Asset Prices?

Prepared by Reginald Darius and Sören Radde ${ }^{1}$

Authorized for distribution by Martin Mühleisen

August 2010

\begin{abstract}
During the period leading up to the global financial crisis many asset classes registered rapid price increases. This coincided with a significant rise in global liquidity. This paper attempts to determine the extent to which the rise in asset prices was influenced by developments in global liquidity. We confirm that global liquidity had a significant impact on the buildup in house prices; however, the impact on equity prices was limited. In contrast to common perception, we find that the impact of global liquidity declined during the period of the Great Moderation. The paper also examines spillovers from global liquidity to domestic variables and concludes that domestic factors generally played a more significant role in house price appreciation relative to global factors. This contradicts the hypothesis of weakened potency of domestic monetary policy in the presence of increased international liquidity.
\end{abstract}

\section{This Working Paper should not be reported as representing the views of the IMF.} The views expressed in this Working Paper are those of the author(s) and do not necessarily represent those of the IMF or IMF policy. Working Papers describe research in progress by the author(s) and are published to elicit comments and to further debate.

JEL Classification Numbers: E31, E44, E52

Keywords: Global Liquidity, Asset Price, Spillover Analysis

Author's E-Mail Address: rdarius@imf.org, sradde@diw.de

\footnotetext{
${ }^{1}$ The authors thank Tam Bayoumi, Martin Mühleisen, Akito Matsumoto and seminar participants at Strategy, Policy, and Review Department of the IMF, for many helpful comments and suggestions.
} 


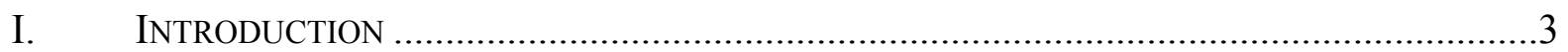

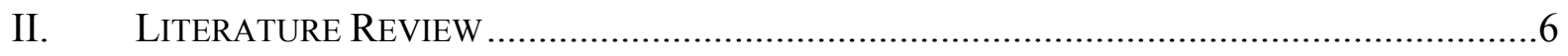

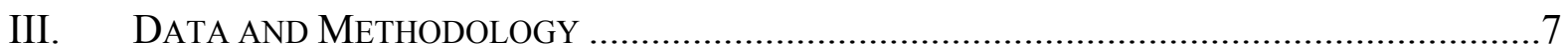

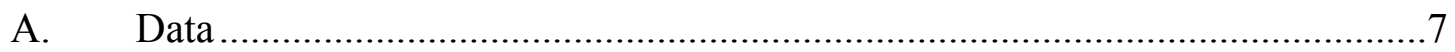

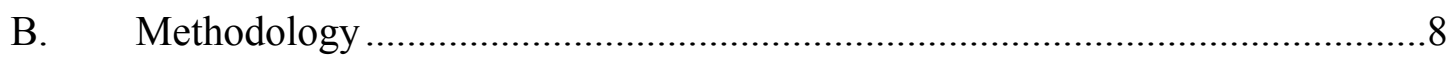

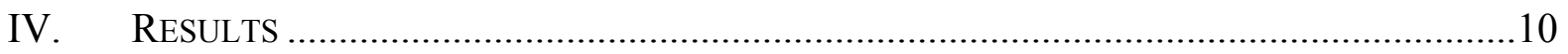

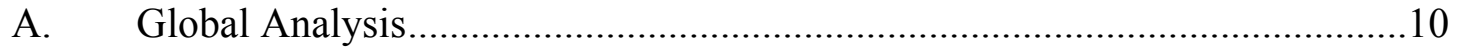

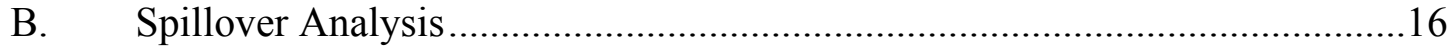

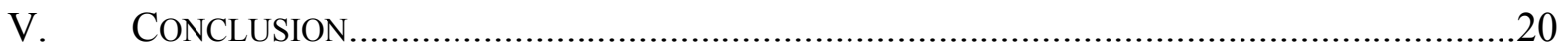

Figures

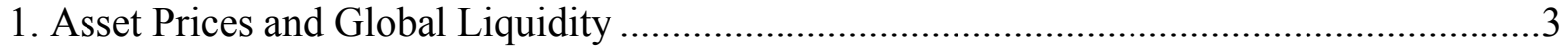

2. Impulse Responses to an Interest Rate Shock and a Liquidity Shock .............................11

3. Impulse Responses to an Interest Rate Shock and a Liquidity Shock, 1971Q1 to1983Q4 .13

4. Forecast Error Variance Decomposition Global Model, 1971Q1 to 1983Q4 ...................14

5. Impulse Responses to an Interest Rate Shock and a Liquidity Shock, 1984Q1-2007Q4 ...15

6. Forecast Error Variance Decomposition Global Model, 1984Q1-2007Q4......................16

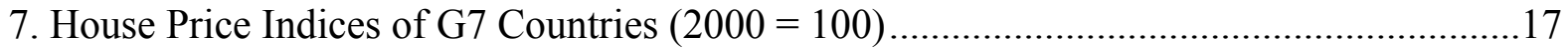

8. Impulse Responses to Global Liquidity Shock and Domestic Liquidity Shock, Japan.......18

9. Impulse Responses to Global Liquidity Shock and Domestic Liquidity Shock, U.S.........19

10. Forecast Error Variance Decomposition Global Model, 1971Q1-2009Q3.....................22

11. Forecast Error Variance Decomposition Global Model, 1983Q1-2009Q3 ......................22

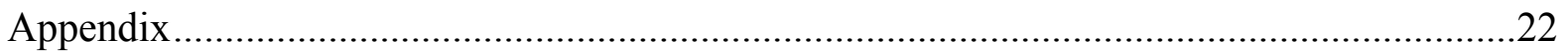

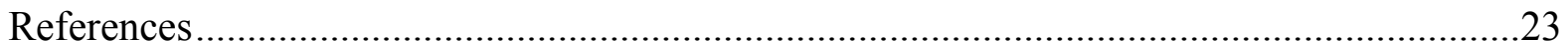




\section{INTRODUCTION}

Interest in the concept of "global liquidity" and its impact on economic growth and inflation around the world has increased in recent years. For example, prior to the recent economic crisis, economists debated whether global liquidity had played a significant role in exerting upward pressure on equity, commodity and house prices. ${ }^{2}$ In the G-7 countries, for example, aggregate house prices more than doubled between 2000 and 2008, while equity prices increased by more than 10 percent over the same period. This coincided with a rapid increase in global commodity prices and particularly the oil price, which at one point exceeded $\$ 140$ per barrel.

Figure 1. Asset Prices1/ (left scale) and Global Liquidity (right scale) (Demeaned annual growth rate; shaded areas indicate global recessions)
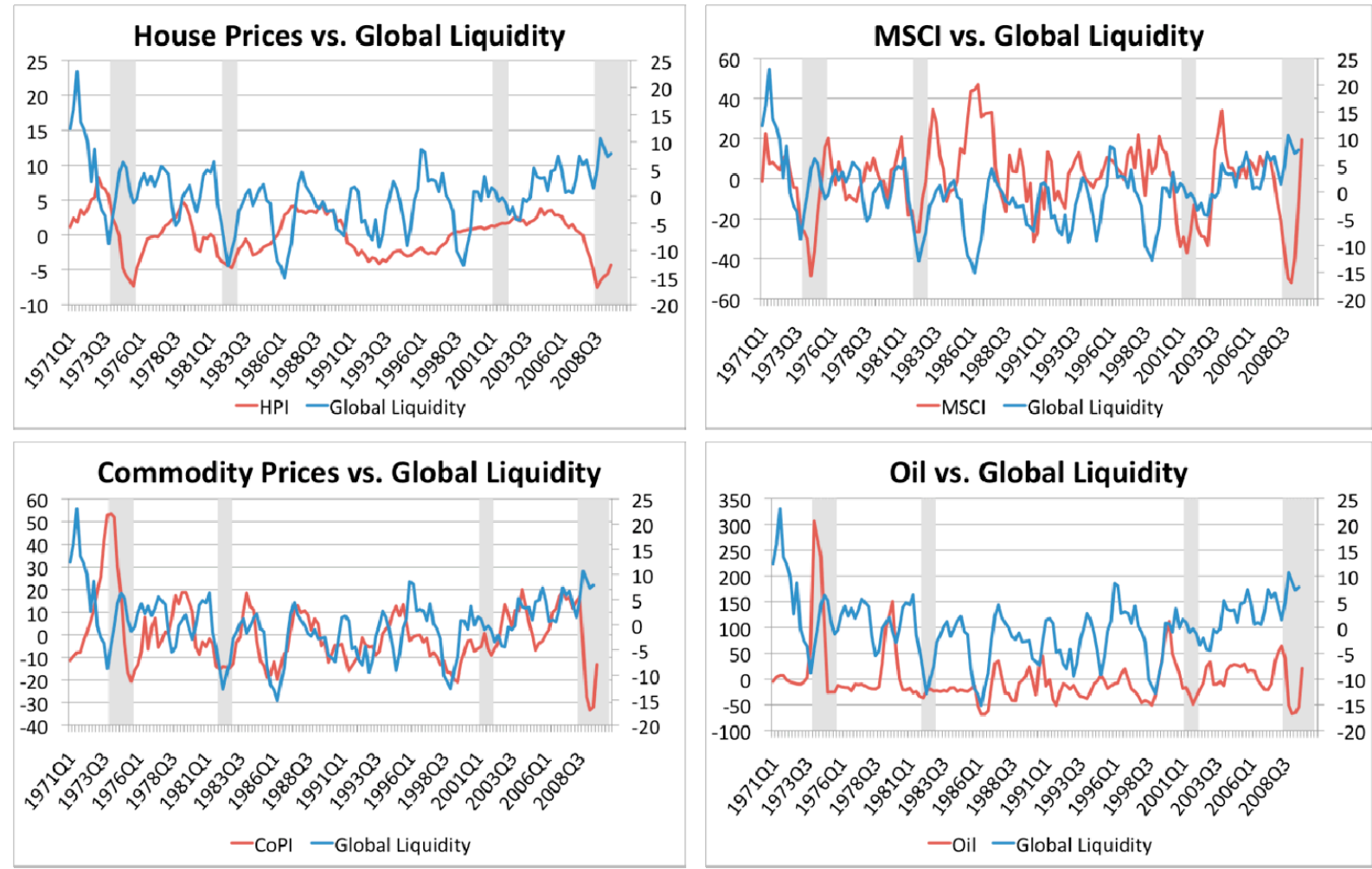

$1 / \mathrm{HPI}$ is the aggregated global house price index, $\mathrm{CoPI}$ is our global commodity price index and $\mathrm{MSCl}$ is the Morgan Stanley Capital International World index.

According to an often-cited hypothesis, ${ }^{3}$ excess global liquidity-fuelled in part by loose monetary policy conditions in the United States — was a driving factor behind the observed

\footnotetext{
${ }^{2}$ It should be noted that there was wide variability in the growth rate of asset prices amongst the G-7 countries and in particular house prices. The USA and the U.K. experienced very large house price increases, whereas the increase in Germany and Japan was less pronounced.
}

${ }^{3}$ See for example King (2006), the Economist of 11 August 2005 and Morgan Stanley (2005). 
surge in asset prices. ${ }^{4}$ If confirmed, an intriguing feature of this concurrent development would be its global dimension. A close relationship between global liquidity and asset prices would foster the emerging view that domestic monetary policy is weakened due to exogenous global factors. Limited potency of domestic monetary policy would hence imply the need for enhanced monetary policy coordination to effectively limit adverse global spillovers. ${ }^{5}$ Moreover, global liquidity measures could play an important role for predicting future trends in global asset prices. This would be important since generating reliable forecasts of asset price movements has proven to be particularly challenging.

The relationship between global liquidity and asset prices is at the heart of this paper. First, we have to grapple with conceptual issues, given the lack of consensus in the literature on how to actually measure global liquidity. In most academic studies (and market analyst reports), global liquidity is generally calculated as an aggregate of broad money supply in the major economies (G7-countries). Alternatively, one could focus on a measure of global liquidity that is based on the speed with which an asset can be converted into a medium of exchange. The U.S. dollar serves as the world's main international currency and is the best available measure of a global medium of exchange. Likewise, international reserves provide such exchange services. Therefore, we construct our global liquidity measure by adding international reserves to U.S. base money. ${ }^{6}$ This indicator of global liquidity differentiates our paper from most other approaches in the literature.

Increases in global liquidity are likely to be associated with a rise in aggregate demand and will thus increase the price of most assets. However, research suggests that, at the domestic level, the impact of liquidity varies depending on the asset class. In particular, since the supply of housing is inelastic relative to other assets, increases in demand associated with rising liquidity are likely to generate stronger price effects, at least in the short-run. This relationship is evident in the work of Belke and Gros (2007), OECD (2005), and Shiller (2005). This contrasts with the relationship between liquidity and consumer goods prices, which are more supply-elastic - in part due to low cost supply from emerging markets - and therefore the short-term price response is weaker. The view on global liquidity taken in this paper is that of a monetary condition, which will affect asset prices before translating into general price inflation.

\footnotetext{
${ }^{4}$ Others, including Bernanke (2005), argue that the imbalances were a result of the global savings glut. A counter argument to this view is provided by Taylor (2009), who argues that loose monetary policy in the U.S. played a major role in domestic asset appreciation during that period.

${ }^{5}$ Hendry (2001) in a study of inflation in the U.K. suggest that domestic money and interest rates had a limited role in inflation or long term interest rates. These findings allude to the fact that global factors might be exerting a large effect on domestic variables.

${ }^{6}$ This measure was introduced in an empirical setting by Matsumoto and Schindler (2006). Using other global currencies like the Euro or the Yen generates similar trends in global liquidity measure.
} 
We examine whether global liquidity is useful in predicting global asset prices (housing, equity and commodity/oil), which registered very rapid growth over the past decade. The paper also seeks to establish whether the impact of global liquidity on asset prices was stable before and during the period between the early to mid-1980s and early 2000s, now commonly referred to as the "Great Moderation". In addition, the paper examines spillovers from global liquidity to domestic liquidity in G-7 countries and assesses the relative impact of global liquidity as a driver of domestic house prices. All of these are all novel contributions to the existing literature on the impact and forecasting properties of global liquidity.

The key results of this study suggest that: (1) global liquidity plays a relatively important role for house price developments, but less so for equity prices. Although global liquidity had a minimal impact on oil prices, we found it to be a more useful predictor of a broad based commodity price index; (2) the results also suggest that the impact of global liquidity varied across the two sub sample periods (1971-83 and 1984-2007). Before 1984, global liquidity had a traceable impact on asset price volatility, but subsequently lost its explanatory power almost entirely for equity prices, and noticeably for housing and commodity prices; (3) spillover effects from global liquidity were found to vary across the G-7 countries, and relative to global factors, domestic factors played a much more significant role in house price developments.

The findings in this paper are broadly in line with previous studies, which used the broad money measure of global liquidity. Our observation of a changing relationship between liquidity and asset prices, however, is a novel result suggesting a systematically different impact on asset prices across our sample periods. Finally, by focusing on spillovers, and examining the relative contributions of global and domestic factors, this paper contributes to the debate on whether the rapid acceleration in asset prices was due to domestic and/or global factors.

The remainder of the paper is organized as follows. Section II will provide a brief overview of the existing literature on global liquidity and highlight the key findings. Section III elaborates on our estimation methodology and data set, including details on how country aggregates were obtained. The following section presents a detailed discussion of the results and key findings of our paper. Section V concludes with a summary of our contributions to the literature and discusses possible avenues for further research. 


\section{LiterATURE REVIEW}

The impact of global liquidity and its relationship with macroeconomic variables and asset prices has gained increasing attention of late. The interest in the role of global liquidity gained increasing prominence in the period preceding the global crisis, driven in part by the emerging view that the impact of domestic policies was overshadowed by global developments. This view was often articulated in the context of the notion of the global savings glut. However, academic research specifically examining the impact of global liquidity factors on the domestic economy remains relatively scarce.

An early study of the effects of global liquidity was conducted by Baks and Kramer (1999), who used growth in broad and narrow money to generate global liquidity indicators. Their findings from simple contemporaneous correlation analysis showed that excess money growth (global liquidity) was negatively correlated with interest rates but positively correlated to stock returns. These findings were confirmed using regression analysis. Baks and Kramer (1999) also found evidence of spillover from excess money in the U.S. to excess money in Japan. Sousa and Zaghini (2006) used a simple sum of monetary aggregate measure of global liquidity to examine the impact of global liquidity shocks on the euro area. The results suggest that global liquidity shocks matter for price and output fluctuations. The findings also indicate that a significant proportion of the variation of euro area M3 is driven by global liquidity.

Rüffer and Stracca (2006) showed that expansionary global monetary shocks generate significant spillovers to the euro area and to some extent Japan. However a composite real asset price index, which includes property and equity, did not appear sensitive to changes in global liquidity. Belke and others, (2010) using cointegrated VAR analysis demonstrate that the inclusion of commodity prices helps to identify a significant role for global liquidity in explaining changes in aggregate demand and inflation. D'Agostino and Surico (2009) find that the information content of global liquidity is superior to domestic factors in forecasting inflation. Giese and Tuxen (2007) find a weak relationship between global liquidity shocks and share prices. Belke and others, (2008) use VAR models to examine the relationship between global liquidity and global asset prices with aggregated OECD data. The results suggest that house prices are relatively sensitive to global liquidity shocks.

Our paper follows closely in the tradition of Belke and others, (2008) in examining the relationship between global liquidity and asset classes. However we extend this analysis in a number of directions. Firstly, we introduce a different measure of global liquidity which focuses less on the broad monetary aggregates and considers the role of international reserves. Secondly we focus on the time varying impact of global liquidity, which attempts to distinguish between the impact of liquidity during the period of the Great Moderation, the later part of which was characterized by rising global liquidity and asset price. 


\section{Data AND Methodology}

\section{A. Data}

We use quarterly data ranging from 1971Q1 to 2009Q3 for our sample consisting of all G7 countries (Canada, France, Germany, Italy, Japan, USA, and U.K.). Although this sample misses a substantial part of world GDP, our global liquidity measure has a truly global dimension (see below.) For each of the above countries we collect data on real GDP $\left(\mathrm{Y}_{\mathrm{i}}\right)$, the GDP deflator $\left(\mathrm{P}_{\mathrm{i}}\right)$, a 3-month nominal interest rate $\left(\mathrm{IS}_{\mathrm{i}}\right)$, a measure of narrow money $\left(\mathrm{M}_{\mathrm{i}}\right)$ and a house price index $\left(\mathrm{HPI}_{\mathrm{i}}\right)$. Moreover, we include two essentially global asset price indices in our analysis - the MSCI World index (MSCI) and the CRB Spot Index - a commodity price index (CoPI) consisting of a basket of internationally traded commodities including oil. The latter are compiled by Morgan Stanley Capital International and the Commodity Research Bureau, respectively.

One novelty in the approach presented in this paper vis-à-vis previous research relates to the introduction of a different global liquidity indicator (M), which is constructed as the sum of the U.S. monetary base (total reserves with the Federal Reserve plus currency) and world international reserves. This measure is intended to capture the availability of a global medium of exchange.

All data are taken from IMF and OECD databases and seasonally adjusted, except for the interest rate, using the X12-ARIMA procedure.

In addition to the global equity and commodity price indices and our global liquidity indicator, we construct global, or more precisely, G7-aggregates from our series on real GDP, the GDP deflator, short-run interest rates as well as the house price index. In doing so we follow the aggregation procedure proposed by Beyer and others, (2001) and applied by Belke and others, (2008), which is used as the benchmark for this analysis. This procedure is three-step. First, all GDP series are converted to some common currency (SDR). From these commonly denominated series, individual country-weights are then calculated as the share of a given country's nominal GDP in total G7-GDP. Country $i$ 's weight at time $t$ is, thus,

$$
w_{i, t}=\frac{e_{i, t}^{S D R} G D P_{i, t}}{\sum_{i} e_{i, t}^{S D R} G D P_{i, t}}
$$

For each variable, the aggregate growth rate at any given time is then determined as the weighted sum of the country-specific growth rates

$$
g_{\text {agg } t}=\sum_{i} w_{i, t} g_{i, t}
$$


Finally, the global variable is obtained in levels by setting an initial value indexed to a base year $(1970=100)$ and multiplying with gross growth rates. This yields the global aggregate of any variable at time $T$ as

$$
\text { index }_{\text {agg } T}=100 \prod_{t=1}^{T}\left(1+g_{\text {aggt }}\right)
$$

\section{B. Methodology}

As outlined in section II, previous research has mainly employed vector-autoregressions (VAR) or vector error correction models (VECM) to investigate the dynamic relationship between global liquidity and asset prices. Unit root tests indeed suggest that all our series are integrated of order one and at least some are cointegrated. Due to these cointegration relationships estimating the model in differences would yield biased estimators, as the error correction term would be omitted. Estimating the model in levels gives asymptotically consistent estimators, in contrast.

As we are primarily interested in the forecasting power of global liquidity for various asset prices, we opt for a VAR-approach. We perform appropriate specification tests and find that our main results are robust to a number of alternative specifications of our model. Lag length criteria (AIC, SC) and the LR test statistic suggest an autoregressive structure of order two. Our baseline model, thus, takes the form

$$
x_{t}=v+\alpha t+\left(A_{1} L+A_{2} L^{2}\right) x_{t}+u_{t}
$$

Our analysis is split up into two sub-chapters. First, we investigate the impact of global monetary factors on a purely global level, i.e., in terms of our global aggregates. Then we proceed to study the impact of global factors on domestic dynamics to flesh out heterogeneous reactions to changes in global monetary conditions. The corresponding vectors of variables are

$$
x_{t}=\left(y_{t}, p_{t}, h p i_{t}, I S_{t}, m_{t}, \operatorname{copi}_{t}, \mathrm{msci}_{t}\right)
$$

for the global model and

$$
x_{t}^{i}=\left(\tilde{y}_{t}, \tilde{p}_{t}, \tilde{I} S_{t}, \tilde{m}_{t}, y_{t}^{i}, p_{t}^{i}, I S_{t}^{i}, h p i_{t}^{i}, m_{t}^{i},\right)
$$

in the spillover analysis. ${ }^{7}$ In both cases, all variables except interest rates enter in logs.

\footnotetext{
${ }^{7}$ Global variables in the spillover analysis are G-6 rather than G-7 aggregates which exclude the country under investigation. Similarly, the global liquidity indicator is corrected for country $i$ 's contribution. These variables are denoted with a tilde.
} 
To obtain impulse response functions and forecast error variance decompositions, the model needs to be transformed in a way that controls for residual correlation in (III-4). Residual correlation, i.e., a non-diagonal covariance matrix $\Sigma_{u} \equiv E\left[u_{t} u_{t}^{\prime}\right]$, implies that shocks to different variables will not occur independently. To identify the effect of a shock to only one variable on the system, the error terms, therefore, have to be orthogonalized. Provided that $\Sigma_{u}$ is positive definite, there exists a lower triangular matrix $P$, such that $\Sigma_{u}=P P^{\prime}$ (Cholesky decomposition). Now let $D$ be a diagonal matrix with its main diagonal identical to that of $P$. Then the Cholesky decomposition of our covariance matrix can be expanded according to

$$
\Sigma_{u}=\left[P D^{-1}\right]\left[D D^{\prime}\right]\left[P D^{-1}\right]^{\prime} \equiv W \Sigma_{\varepsilon} W^{\prime}
$$

where $\Sigma_{\varepsilon}$ is a diagonal matrix with positive elements and $W$ lower triangular with unit main diagonal. Finally, for ease of exposition assume a VAR(p) process without constant. Premultiplying such a $\operatorname{VAR}(\mathrm{p})$ by $W^{-1}$ yields

$$
W^{-1} y_{t}=W^{-1}\left(A_{1} L+A_{2} L^{2}\right) y_{t}+\varepsilon_{t}
$$

where $\varepsilon_{t}=W^{-1} u_{t}$ and

$$
\Sigma_{\varepsilon}=E\left[\varepsilon_{t} \varepsilon_{t}^{\prime}\right]=W^{-1} E\left[u_{t} u_{t}^{\prime}\right]\left(W^{-1}\right)^{\prime}=W^{-1} \Sigma_{u}\left(W^{\prime}\right)^{-1}
$$

Hence, such a transformation is suitable to generate orthogonal residuals with diagonal covariance matrix $\Sigma_{\varepsilon}$. However, in doing so, we impose some structure on our original system. As $W$ is a lower triangular matrix, so is $W^{-1}$. Looking at the transformed error term shows that as a result of the structure of $W^{-1}$ a shock $u_{l t}$ to any original variable $y_{l t}$ cannot have an instantaneous effect on any variable $y_{k t}$ with $k<l$, as $\varepsilon_{k t}$ is only a function of any $u_{i t}$ with $i<k$. In other words, a shock to any variable $l$ in our vector $y_{t}$ can affect all subsequent variables, but none occurring before $y_{l t}$. Hence, this transformation is sensitive to the ordering of our variables.

The vectors (III-5) and (III-6) represent the Cholesky ordering of our variables for the respective models. Within each block - global or domestic - this choice follows the literature and reflects the relative sluggishness of variables' response to shocks. For example, while output contemporaneously affects inflation, both of these variables do not respond immediately to shocks to the other variables in the system. In the spillover analysis it is also assumed that domestic factors lag behind global factors. ${ }^{8}$

\footnotetext{
${ }^{8}$ Note that this implies an inconsistency in the identifying assumptions underlying our different models. While in the global analysis, a shock to any country $i$ 's GDP can affect all other global variables in line with its share of global GDP-this channel is absent in the spillover analysis.
} 
The results of the spillover analysis should be interpreted with some caution due to the effects of the changing composition of the G6 aggregate. For example, in the analysis for the U.S., Japan is part of the G6 aggregate thus contemporaneously affecting the U.S., while domestic U.S. shocks cannot affect Japan. However, in the spillover analysis for Japan, the U.S., in turn, is part of the G6 aggregate, thereby potentially exerting a contemporaneous influence on Japan, which contradicts the first model.

\section{Results}

\section{A. Global Analysis}

\section{Does Liquidity Matter? Full Sample Analysis}

We begin our analysis by looking at our global model over the entire sample period from 1971Q1 to 2009Q3. Figure 2Figure 2 shows the impulse responses to temporary monetary shocks, where an interest rate shock is included as a plausibility-check. As an unanticipated increase in the nominal interest rate corresponds to a contractionary monetary shock, economic activity declines and asset prices shrink as expected. However, as in many related studies, we observe a prize puzzle, i.e., an initially positive reaction of the price level to the interest rate shock. This is commonly interpreted as indicating the lack of variable capturing long-term inflation expectations. ${ }^{9}$

A positive shock to global liquidity, on the other hand, carries the opposite sign and corresponds to a monetary expansion. Interestingly - and in line with previous studies (see Belke and others, (2008)) —, global liquidity shocks have a sluggish, but persistent impact on house and commodity prices, while there is no significant response of equity prices. ${ }^{10}$ The overall price level only picks up with a substantial lag. These broad results are confirmed by the forecast error variance decomposition of the above variables (see Appendix, Figure 10.)

\footnotetext{
${ }^{9} \mathrm{We}$ observe the price puzzle despite the inclusion of a commodity price index (CoPI), which includes crude oil prices. This hints at the fact that our CoPI does not capture long-term inflation expectations.

${ }^{10}$ The persistence of some impulse responses to temporary shocks highlights the nonstationary nature of the underlying processes.
} 
Figure 2. Impulse Responses to an Interest Rate Shock (left column) and a Liquidity Shock (right column)

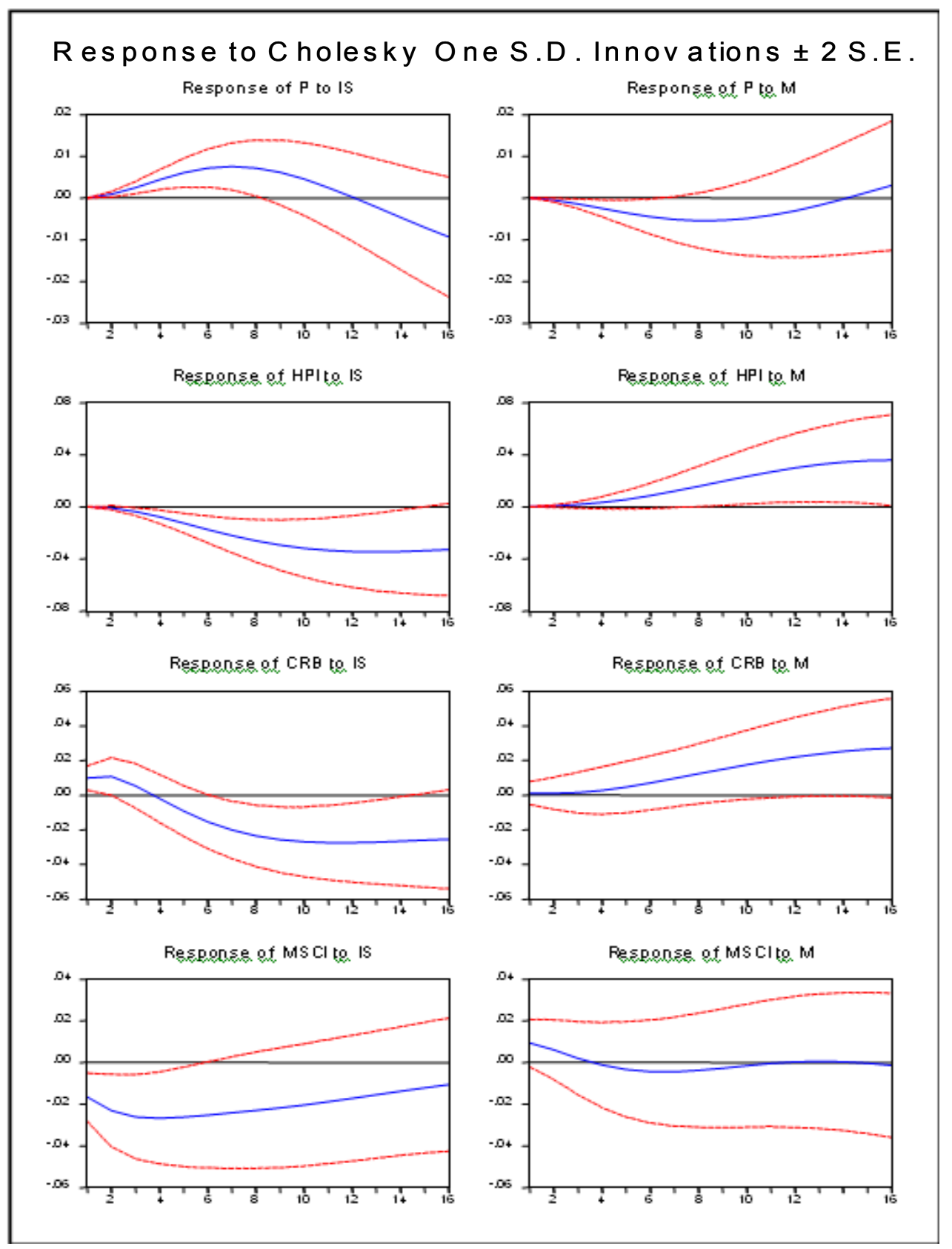

\section{A Dynamic Relationship? Pre-1984 vs. Great Moderation}

However, there is reason to believe that the global economic environment changed considerably over our sample period. While the 1970 s and early 1980 s were characterized by high volatility due to international shocks and poor monetary policy performance regarding price stability, the subsequent decades witnessed much more stable economic conditions up until the global financial crisis from 2008-09. This period, starting somewhere in the early to mid-1980s and now commonly dubbed the 'Great Moderation', saw rapid global economic 
integration, a switch in the monetary policy regime due to higher credibility of domestic monetary policy led by the U.S. and burgeoning financial innovation which potentially contributed to the massive increase in market liquidity.

Following McConnell and Perez-Quiros (2000) and Blanchard and Galí (2008), we split our sample based on this assessment into two sub-periods. During the first period from 1971Q1 to 1983Q4, i.e., pre Great Moderation, the impulse responses to a global liquidity shock of house prices and also equity (in the short run) are significant. Moreover, global liquidityand to an even larger extent also the nominal interest rate-explains a substantial share of asset price volatility, as revealed by the variance decomposition (see Figure 4.) 
Figure 3. Impulse Responses to an Interest Rate Shock (left column) and a Liquidity Shock (right column), 1971Q1 to 1983Q4

Response to $C$ holesky One S.D. Innov ations \pm 2 S.E.
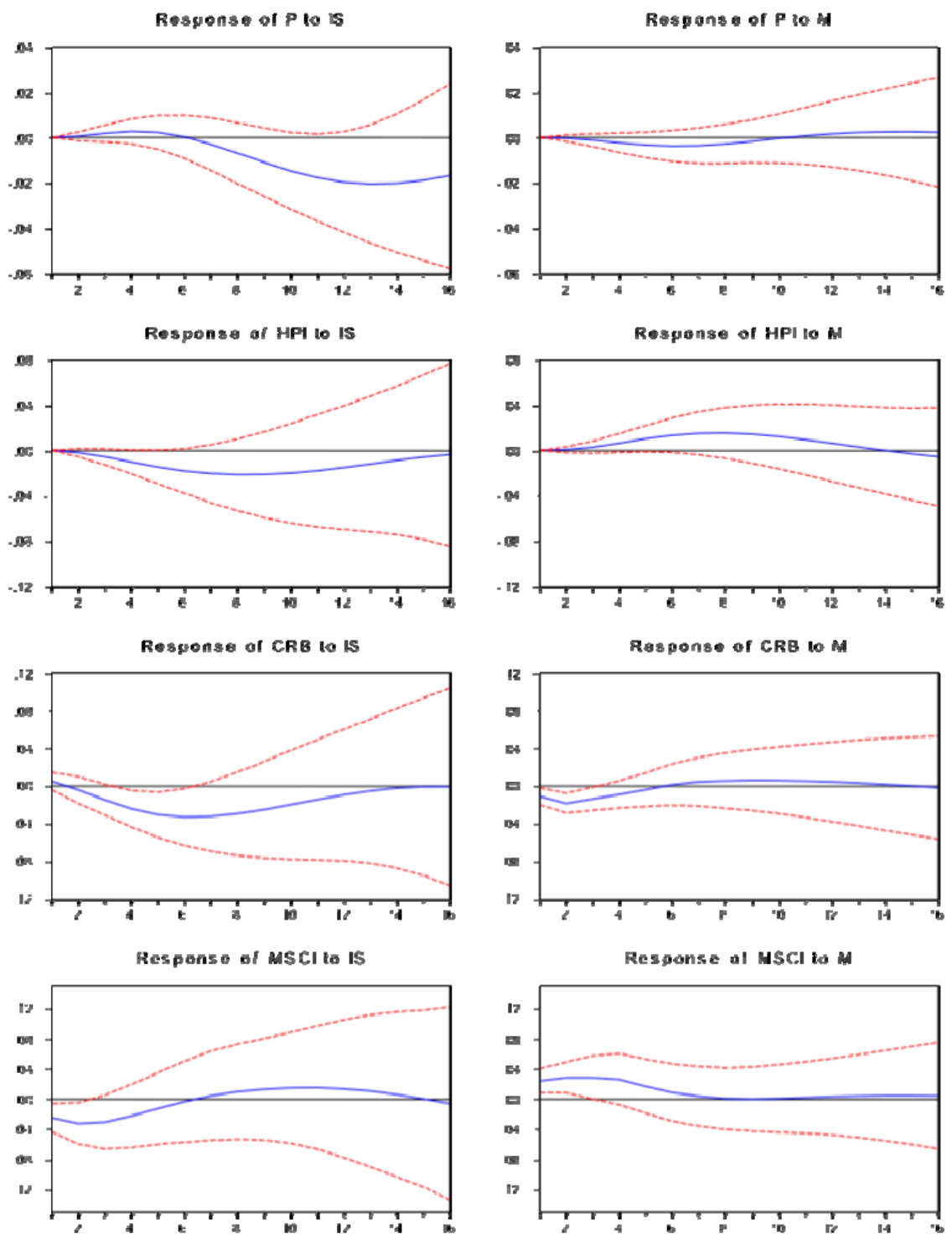
Figure 4. Forecast Error Variance Decomposition Global Model, 1971Q1 to 1983Q4
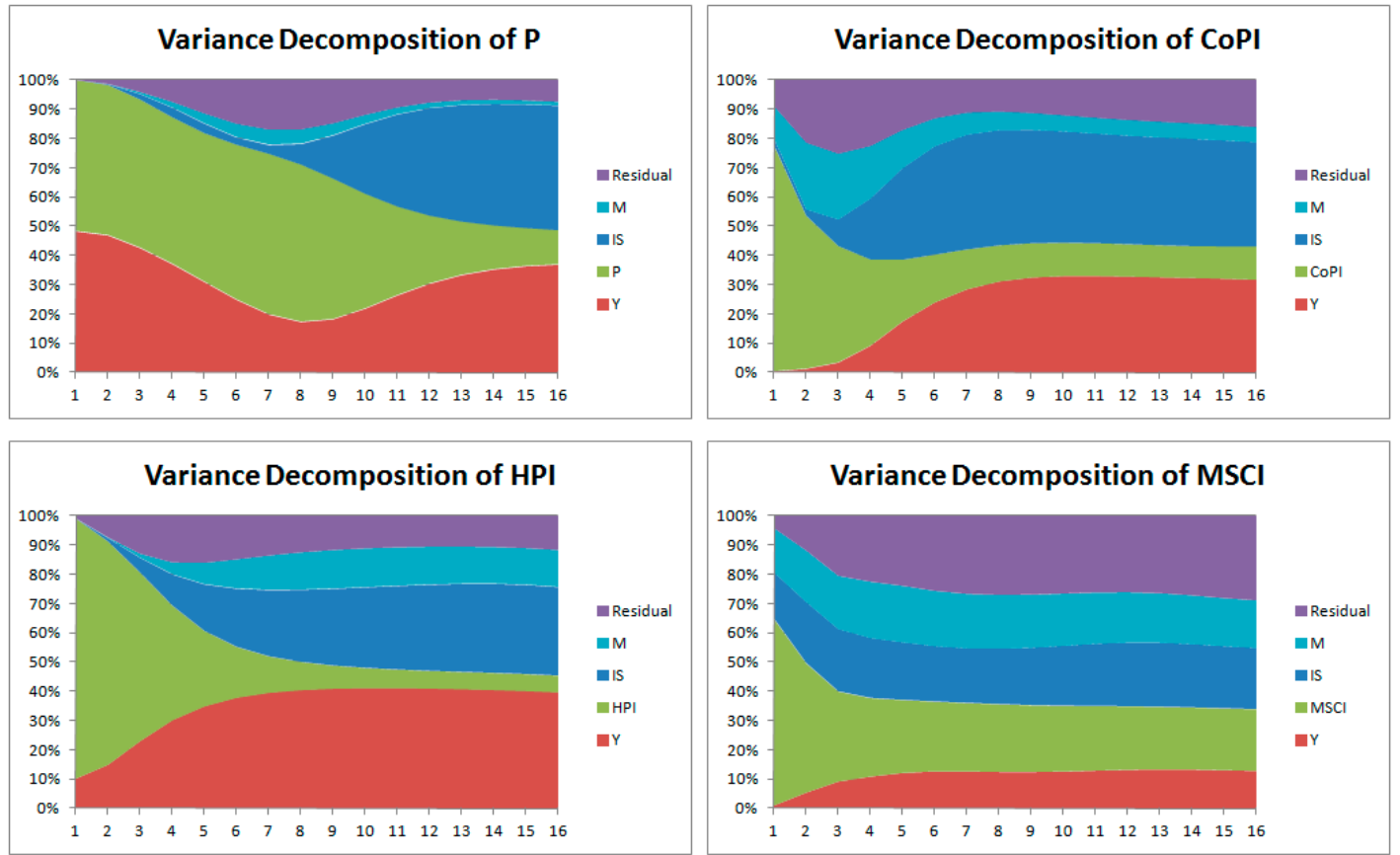

During the Great Moderation, i.e., from 1984Q1 to 2007Q4, strikingly different results obtain as shown in Figure 5 Figure 5andFigure 6. First, the impulse responses to a liquidity shock become largely insignificant. Secondly, global liquidity looses most of its forecasting power for equity and house prices and only retains some for commodity prices. This finding suggests that the relationship between global liquidity and asset prices changed between the two sample periods. Contrary to common perception, the impact of liquidity on asset prices even seems to have weekend during the Great Moderation. This observation apparently contradicts the claim that abundant global liquidity fuelled the housing bubble, which countries like the U.S., the U.K. and Spain experienced in the run-up to the financial crisis.

However, in this context it should be noted that rather than explaining the long-run behaviour of asset prices, global liquidity might asymmetrically affect asset prices given the state of the economy or the tightness of a particular market. We will revisit such arguments in our concluding section. 
Figure 5. Impulse Responses to an Interest Rate Shock (left column) and a Liquidity Shock (right column), 1984Q1-2007Q4

Response to $C$ holesky One S.D. Innov ations \pm 2 S.E.
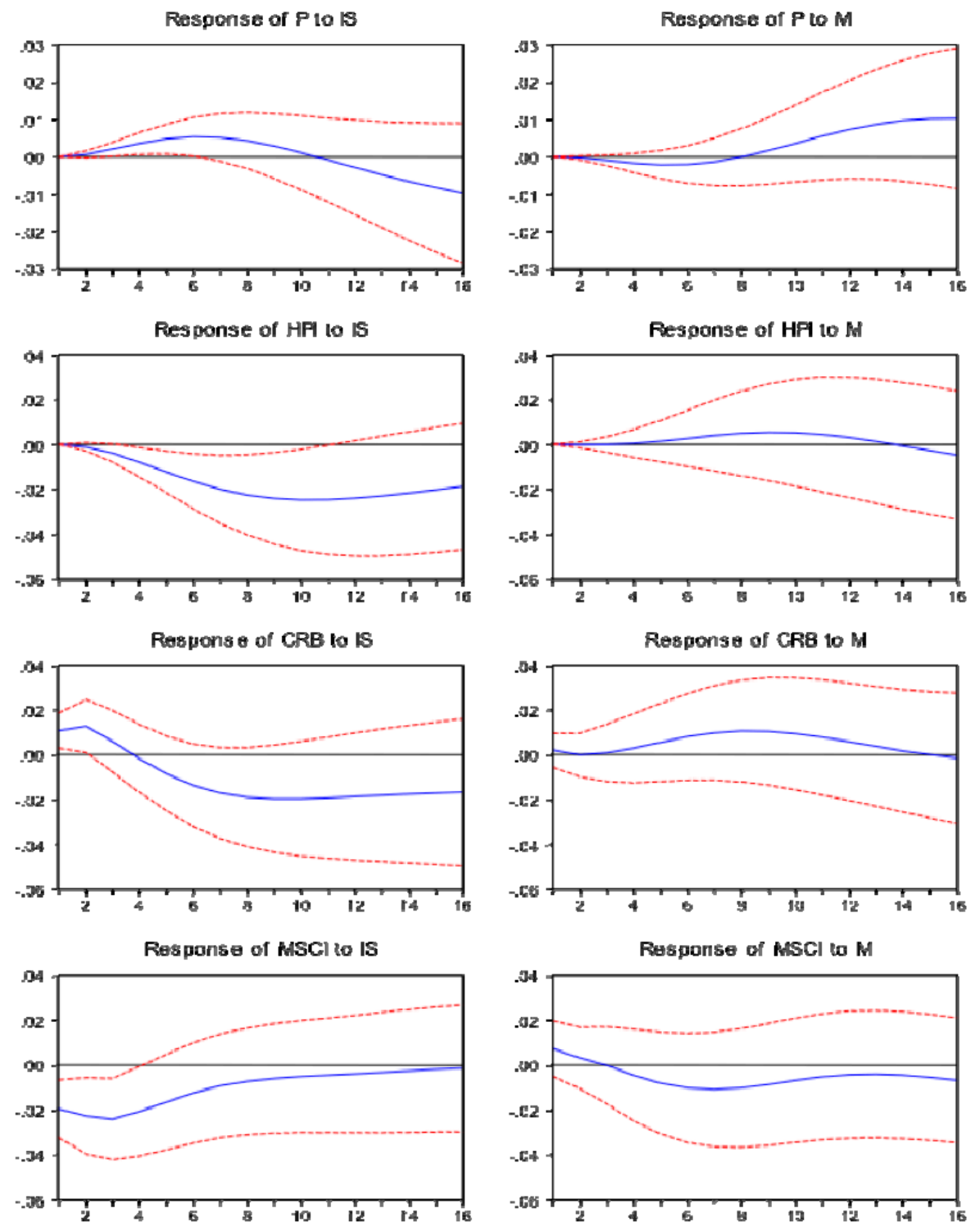
Figure 6. Forecast Error Variance Decomposition Global Model, 1984Q1-2007Q4

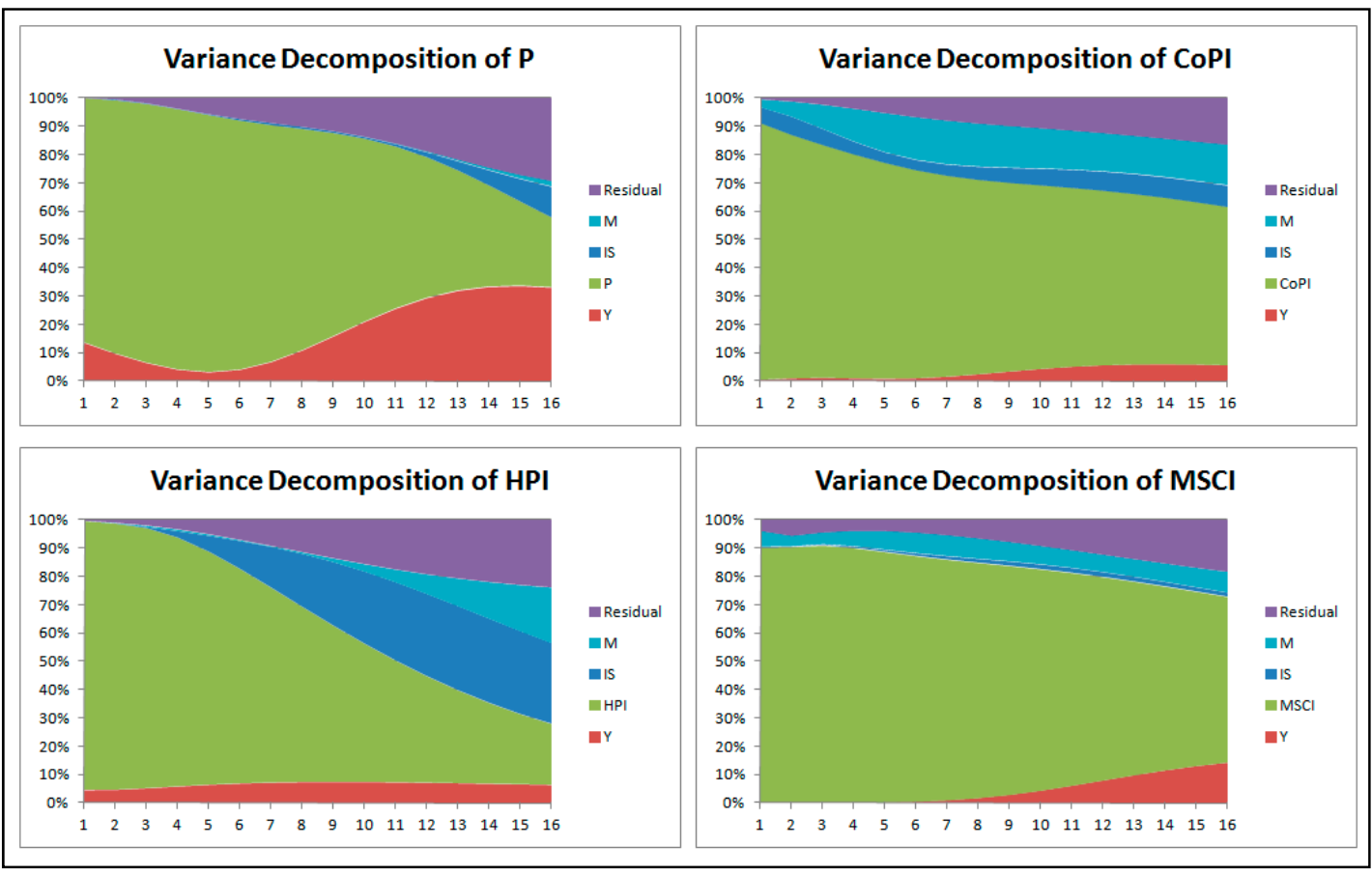

Liquidity looses almost all its predictive power for asset prices when the second sub-sample is extended to include the period of global financial crisis in 2008-09 (see Appendix, Figure 11.) This is not surprising, as it is well established that monetary policy strongly leaned against the wind, i.e., expanded liquidity while the economy was ailing and asset prices collapsed. In such periods of global crisis, we would, thus, expect a negative rather than positive relationship between liquidity and asset prices. At least between boom- and bustphases of the business cycle we should thus not treat the impact of liquidity on asset prices as symmetric and time-invariant. This fact further speaks to the changing nature of the underlying relationship alluded to in the previous paragraph.

\section{B. Spillover Analysis}

Thus far, our analysis suggests that when it mattered, global liquidity had a strong impact on house prices relative to other asset classes. This is not altogether surprising, as it is reasonable to expect a sharper impact of liquidity surges on asset classes with relatively small price elasticity of supply (as is the case in the housing market). However, contrary to commodity prices in particular and - to a lesser extent - equity prices, house prices are not global in nature. Here, aggregation comes at the price of concealing substantial heterogeneity across countries. While countries such as the U.S. and the U.K. were experiencing very strong housing bubbles, the opposite was actually true for Japan and Germany as shown in Figure 7. 
Figure 7. House Price Indices of G7 Countries $(2000=100)$

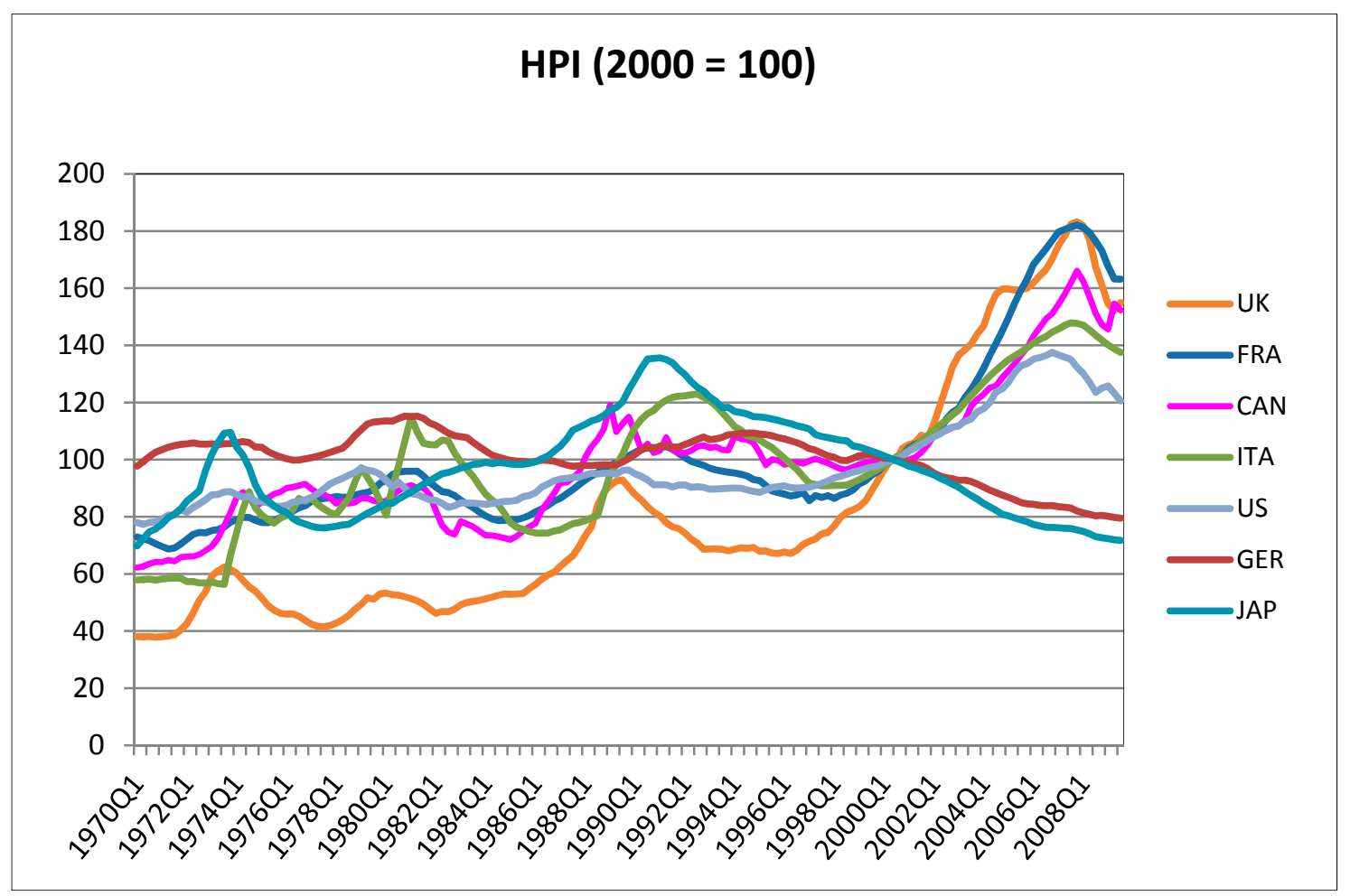

Can these differences be explained by an asymmetric impact of global liquidity on the respective countries? To answer this question, we perform a spillover analysis by estimating the impact of G6- versus domestic variables on house prices as detailed in chapter III.B. To take an extreme case, we focus on our results for Japan and the U.S. Although a global liquidity shock contributes positively to the overall price level in Japan, house prices respond neither to global nor domestic shocks in a significant way. Given that Japan did not witness a housing bubble, this result is consistent with intuition. 
Figure 8. Impulse Responses to Global Liquidity Shock (left column) and Domestic Liquidity Shock (right column); Bottom-Variance Decomposition Japan. 1971Q1-2009Q3

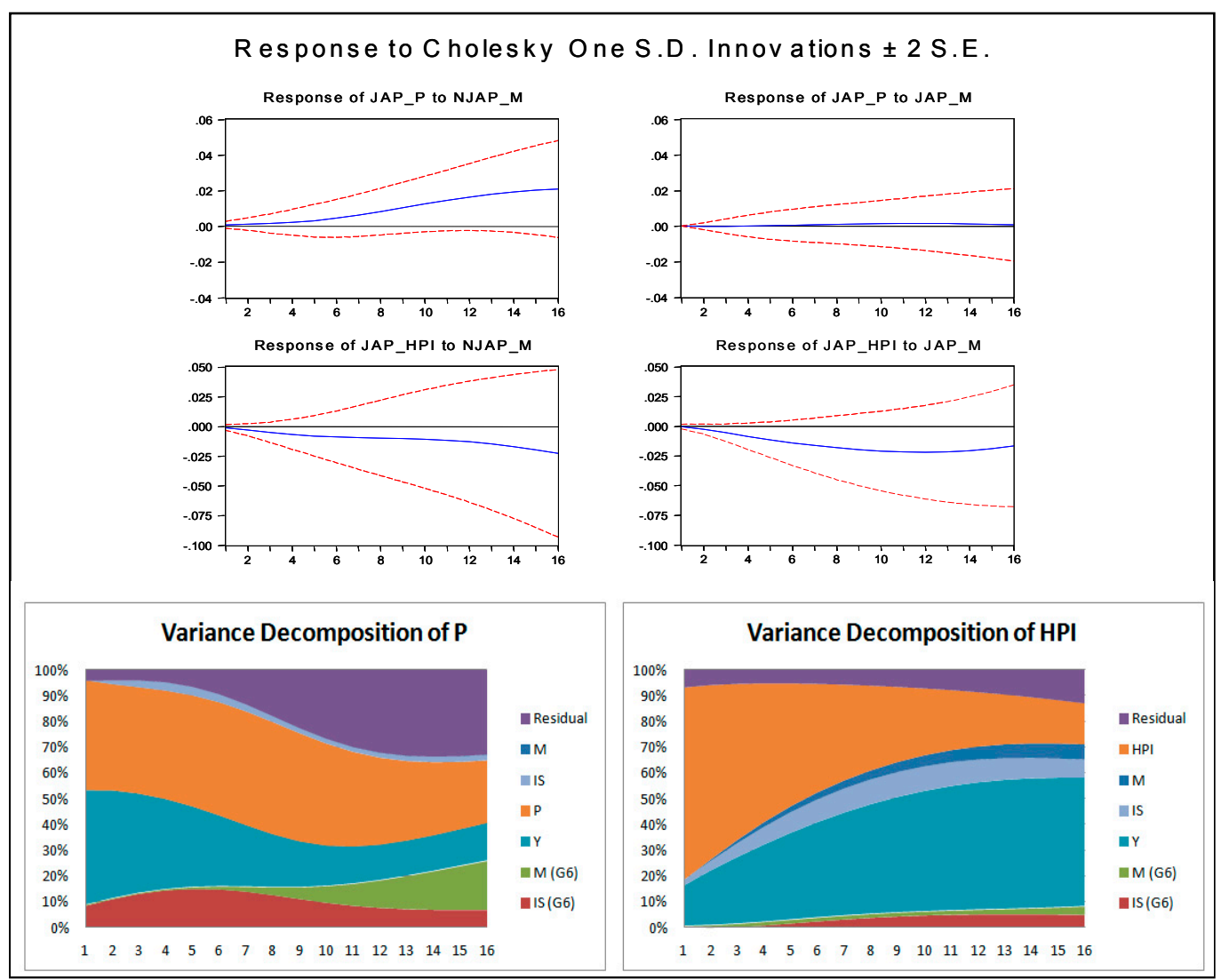

According to the claim that global liquidity and international search for yield contributed heavily to blowing up the U.S. real estate bubble, a similar exercise should conclude that the U.S. house price index responds strongly to a global (G6-) liquidity shock. As revealed by the impulse response functions and the forecast error variance decomposition in Figure 9, domestic rather than global liquidity shocks drive and forecast house prices in the U.S. in our analysis.

This result appears to contradict the argument that the global savings glut contributed to the buildup of asset price bubbles. Moreover, it also challenges the notion of weakened potency of domestic monetary policy in the presence of increased international liquidity. One possible explanation is that our measure of global liquidity fails to capture the expansion in liquidity associated with the shadow banking system, particularly in the United States. ${ }^{11}$ However

\footnotetext{
${ }^{11}$ Pihlman and Hoorn (2010) note that central bank reserves represented a significant source of funding for commercial banks of reserve currency areas. The increase in central bank funding, mainly in the form of deposits, was part of an aggressive diversification strategy and an attempt to increase the returns on reserve holdings.
} 
such a critique ignores the fact that a large proportion of global reserves (including that owned by large surplus countries such as China) were invested in financial assets in advanced economies which provided the basis for the expansion in global liquidity. In that sense, one would expect the measure of global liquidity used in this paper to at least partially capture some of the expansion in (less high-powered) market liquidity. In addition, using international reserves to fund the U.S. federal deficit (purchase of treasury bills) indirectly reduced the domestic demand for government funding thereby allowing for more domestic resources to finance private credit expansion.

Figure 9. Impulse Responses to Global Liquidity Shock (left column) and

Domestic Liquidity Shock (right column);

Bottom-Variance Decomposition U.S., Sample 1971Q1-2009Q3

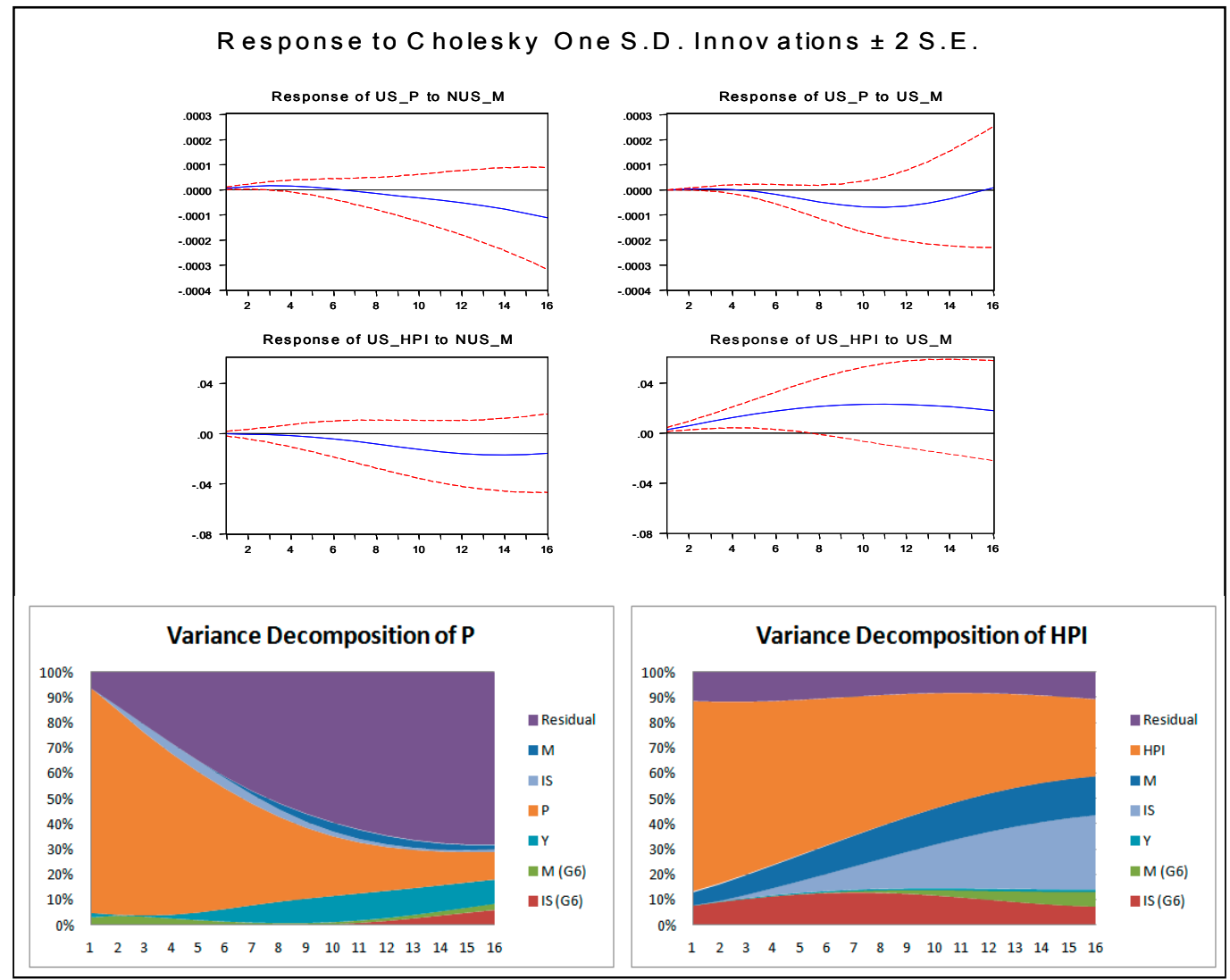




\section{CONCLUSION}

This paper complements the literature on the impact of global liquidity on asset prices in particular by introducing a different measure of global liquidity. We find an asymmetric impact of global liquidity on asset prices classes - with a much stronger effect on house prices compared to equity and commodity prices. This result is broadly consistent with the findings of other studies in the literature and vindicates the use of an alternative measure of global liquidity, which captures more broadly developments in the global medium of exchange. This paper also establishes that there are important differences in the impact of global liquidity before and during the period of the Great Moderation. Specifically, the observation that the impact of global liquidity was lower during the period of the Great Moderation is counterintuitive. Moreover, the inclusion of the crisis years 2008-09 in the later sample results in a nearly complete loss of predictive power of global liquidity for asset prices. This observation suggests that during crises, liquidity and asset prices move in opposite directions due to expansionary monetary policy. This hints at a potentially asymmetric relationship between boom and bust phases.

The results of the spillover analysis point to differences across the countries considered (USA and Japan). Our most striking result is the observation that domestic factors played a much greater role than global factors in house price developments. This finding confirms the perception that house price developments are more closely connected to domestic factors, including monetary policy. This suggests that - contrary to the view of policy makers in a number of countries including the U.S. - monetary policy tools might have been effective in confronting the risk emanating from the housing market.

As the results of this study support a rather unorthodox view of the role of global liquidity in the recent boom and its relevance relative to domestic factors, they indicate essentially two key areas for future research. The first pertains to the adequacy of our global liquidity indicator - and related indicators, for that matter - as such. One might argue, that the significance of global liquidity has declined over time as market and outside liquidity have decoupled due to soaring financial innovation since the late 1980s. This would help explain both, the declining impact of global liquidity during the Great Moderation and its marginal role relative to domestic factors in explaining house price developments. Therefore, one crucial research question is whether the medium of exchange measure used in this study adequately captures the expansion in liquidity associated with the shadow banking systemand if not so, how to develop an adequate indicator of "global" market liquidity.

A second avenue towards tackling the dynamic impact of global liquidity would focus on the hypothesis of an inherently asymmetric relationship between asset prices and liquidity. According to this train of thought, global liquidity would have a more pronounced impact during boom than in bust phases or during the buildup of bubbles in certain asset markets, when prices are less driven by fundamentals. The stronger impact of our liquidity measure on 
a broad commodity index than on oil can be seen as a piece of evidence in favour of this view, as a broad index naturally picks up a greater number of bubbles. The econometric challenge in implementing this approach lies in the design of a model which endogenously identifies regime switches between such bubble/no-bubble phases. 


\section{Appendix}

Figure 10: Forecast Error Variance Decomposition Global Model, 1971Q1-2009Q3
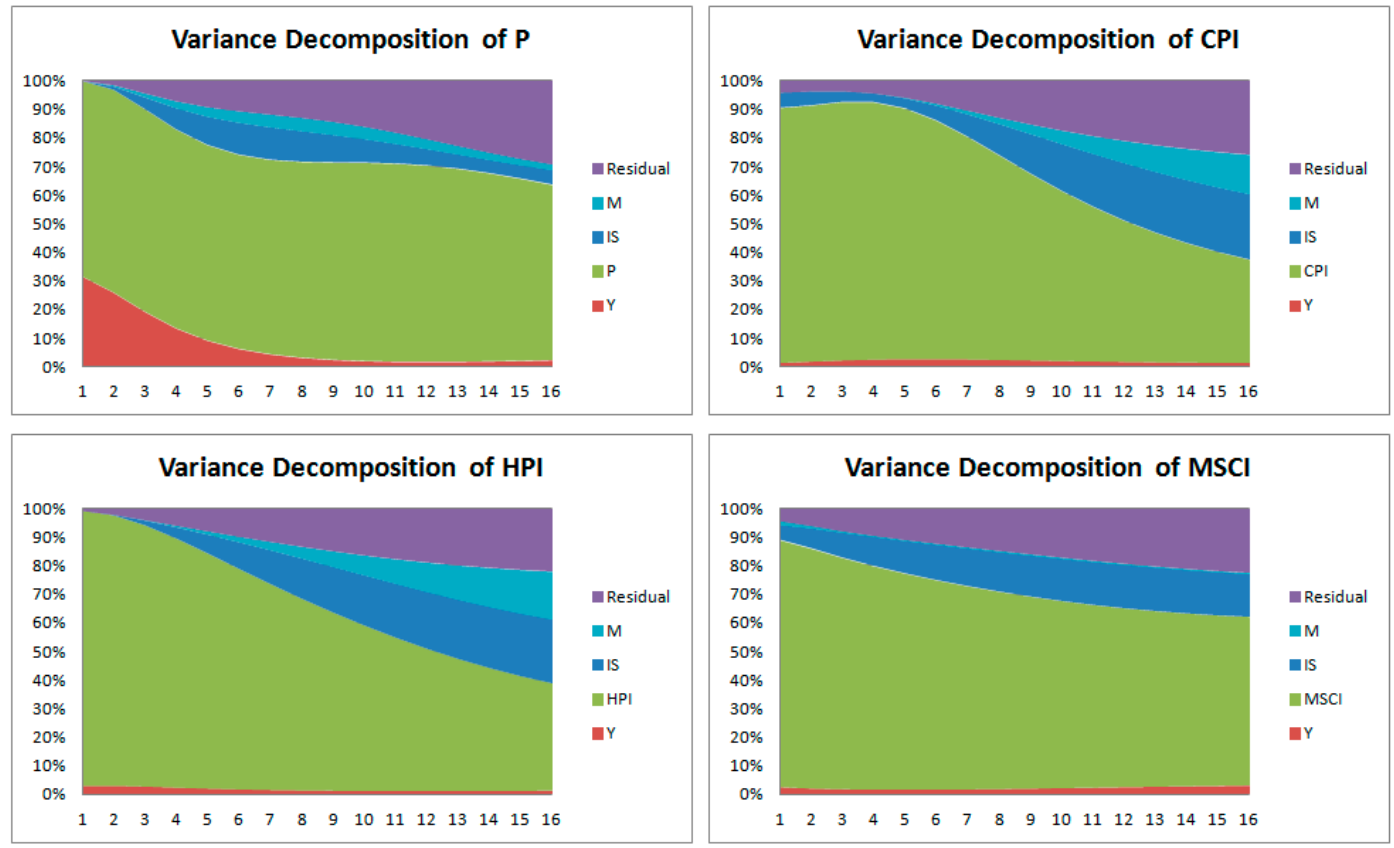

Figure 11. Forecast Error Variance Decomposition Global Model, 1983Q1-2009Q3
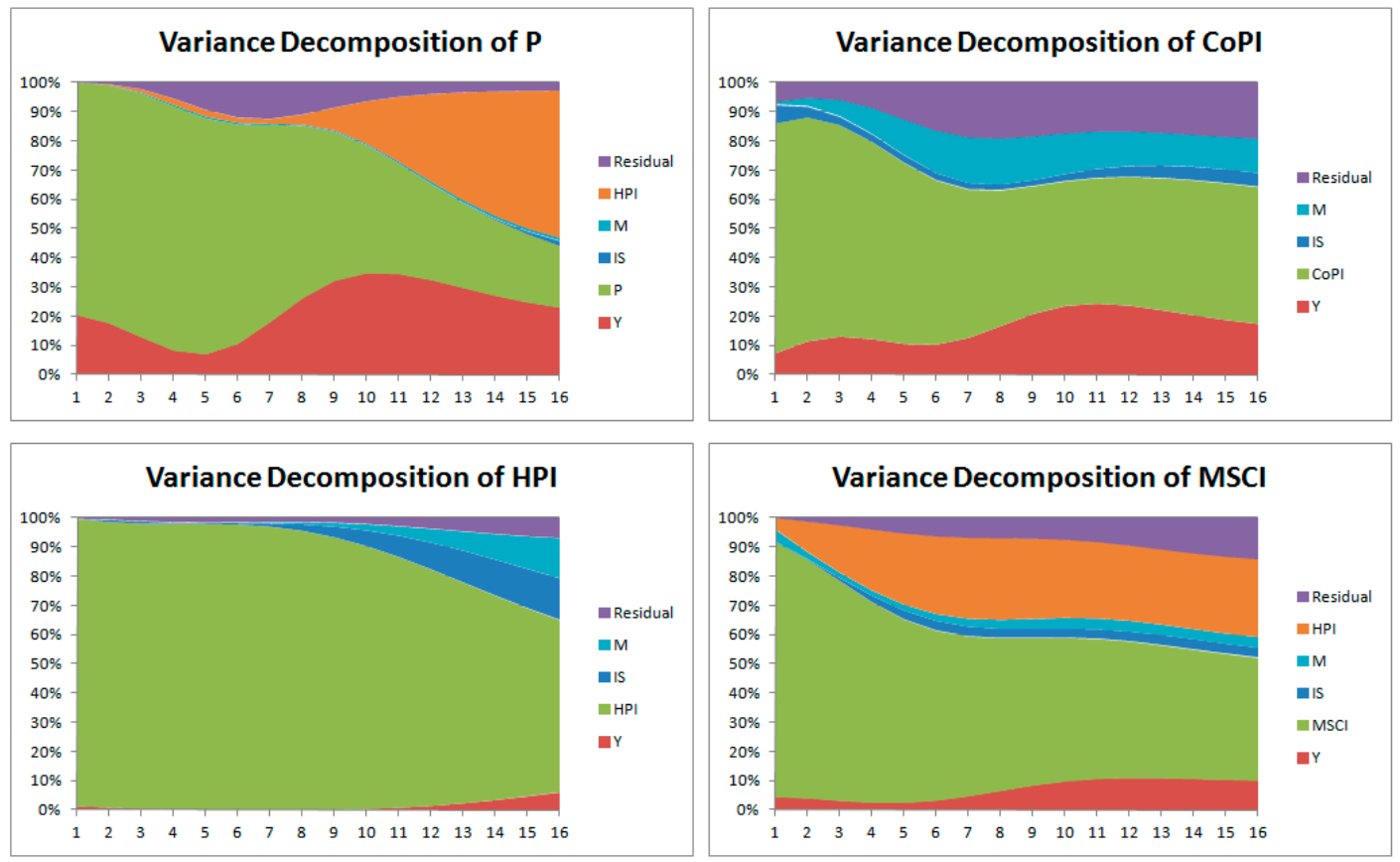


\section{References}

Adrian, T., Shin, H.S., 2008, “Liquidity, Monetary Policy and Financial Cycles," Current Issues in Economics and Finance 14, Federal Reserve Bank of New York.

Baks, K., Kramer, C., 1999, "Global Liquidity and Asset Prices: Measurement, Implications and Spillovers," IMF Working Paper No. 99/168 (Washington).

Belke, A., Bordon, I., Hendricks, T., 2010, "Monetary Policy, Global Liquidity and Commodity Price Dynamics," Discussion Papers No. 971 (DIW Berlin: German Institute for Economic Research).

Belke, A., Orth, W., Setzer, R., 2008, "Sowing the Seeds of the Subprime Crisis-Does Global Liquidity Matter for Housing and Other Asset Prices," International Economics and Economic Policy Vol. 5(4), pp. 403-24.

Belke, A., Gros, D., 2007, "Instability of the Eurozone? On Monetary Policy, House Prices and Labor Market Reforms," IZA Discussion Papers No. 2547, Institute for the Study of Labor (IZA).

Bernanke, B., 2005, "The Global Saving Glut and the U.S. Current Account Deficit," remarks presented at the Sandridge Lecture, Virginia Association of Economics (Richmond: Virginia).

Beyer, A., Doornik, J., Hendry, D.F., 2001, “Constructing Historical Euro-zone Data," Economic Journal Vol. 111, pp. 308-27.

Blanchard, O., Galí, J., 2008, “The Macroeconomic Effects of Oil Price Shocks: Why are the 2000s so Different from the 1970s?” Working Paper (MIT: Department of Economics).

D’Agostino, A., Surico, P., 2009, “Does Global Liquidity Help to Forecast U.S. Inflation?” Journal of Money, Credit, and Banking Vol. 41, pp. 479-89.

Dreger, C., Wolters, J., 2009, "Liquidity and Asset Prices: How Strong are the Linkages?" Discussion Papers No. 860, DIW Berlin, German Institute for Economic Research.

Giese, J.V., Tuxen, C.K., 2007, “Global Liquidity and Asset Prices in a Cointegrated VAR,” manuscript.

Hendry, D.F., 2001, “Modelling U.K. Inflation, 1875-1991.” Journal of Applied Econometrics, Vol. 16, pp. 255-75.

King, M., 2006, Speech delivered at a dinner for Kent Business Contacts (January 16).

Matsumoto, A., Schindler, M., 2006, “Global Monetary Conditions and Liquidity: Measurement and Implications," IMF Research Note (Washington). 
McConnell, M., Perez-Quiros, G., 2000, "Output Fluctuations in the United States; What Has Changed Since the Early 1980s?" American Economic Review, 90-5, December, pp. 1464-76.

Morgan, Stanley, 2005, “Is Global Excess Liquidity Drying Up?” Global Economic Forum (November 8).

OECD, 2005, "Recent House Price Developments: The Role of Fundamentals," Economic Outlook No. 78, Chapter III, pp. 193-234 (Paris).

Rüffer, R., Stracca, L., 2006, “What is Global Excess Liquidity, and Does it Matter?” ECB Working Paper No. 696 (European Central Bank: Frankfurt).

Shiller, R., 2005, “Irrational Exuberance," 2nd ed., Princeton University Press (Princeton: New Jersey).

Sousa, J.M., Zaghini, A., 2006, "Global Monetary Policy Shocks in the G5: A SVAR Approach,” Working Paper Series 2006/30 (Center for Financial Studies: Frankfurt).

Taylor, J., 2009, "The Need to Return to a Monetary Framework," paper presented at the NABE Panel at the AEA Meetings. 